\title{
Plasma Fibrinogen Predicts the Prognosis of Bladder Cancer Patients After Radical Cystectomy
}

This article was published in the following Dove Press journal:

Cancer Management and Research

\section{Shuai Yang* \\ Han Guan (1D* \\ Sheng Wang \\ Hongliang Wu \\ Wenyan Sun \\ Zhijun Chen \\ Qingwen Li (D)}

Department of Urology, The First Affiliated Hospital of Bengbu Medical College, Bengbu, Anhui 233000, People's Republic of China

*These authors contributed equally to this work
Correspondence: Qingwen Li; Zhijun

Chen

Department of Urology, The First Affiliated Hospital of Bengbu Medical

College, Bengbu, Anhui 233000, People's

Republic of China

$\mathrm{Tel} / \mathrm{Fax}+86-552-3086153$

+86-I3956356I52

Email bymnlqw@163.com;

1084243167@qq.com
Background: This study aimed to determine the potential utility of plasma fibrinogen as a prognostic factor in patients with bladder cancer (BCa) after radical cystectomy (RC).

Methods: Patients with BCa who underwent RC from 2014 to 2019 were analyzed retrospectively. The indexes of plasma coagulation and fibrinolysis system factors were collected. Kaplan-Meier survival curves were used to calculate the overall survival (OS) and diseasefree survival (DFS). The prognostic value of plasma fibrinogen was analyzed by using Cox regression model, and a nomogram of $\mathrm{BCa}$ based on plasma fibrinogen was generated by R software.

Results: Among 145 patients, the optimal cut-off value of plasma fibrinogen was $3.14 \mathrm{~g} / \mathrm{L}$. High level of plasma fibrinogen was related to the poor prognosis of patients with $\mathrm{BCa}$, and plasma fibrinogen has a more accurate prognostic ability than other plasma coagulation and fibrinolysis system factors. Multivariate Cox regression analysis showed that plasma fibrinogen was an independent predictor of OS (>3.14 vs $\leq 3.14 \mathrm{HR}, 2.58,95 \% \mathrm{CI}=1.28-5.23$; $\mathrm{p}=0.008)$ and DFS (>3.14 vs $\leq 3.14 \mathrm{HR}, 2.60,95 \% \mathrm{CI}=1.20-5.65 ; \mathrm{p}=0.016)$, and the nomogram based on plasma fibrinogen had better accuracy and discrimination (area under the curve (AUC): OS $=0.741, \mathrm{DFS}=0.733$ ).

Conclusion: Plasma fibrinogen can be used as an independent predictor of OS and DFS for $\mathrm{RC}$ patients, and the nomogram based on plasma fibrinogen was a reliable model for predicting the prognosis after $\mathrm{RC}$.

Keywords: bladder cancer, plasma fibrinogen, radical cystectomy, prognosis, nomogram

\section{Introduction}

Bladder cancer $(\mathrm{BCa})$ is a common malignant tumor in the urinary system. There are an estimated 81,400 new cases and 17,980 deaths in the United States in 2020. ${ }^{1}$ Muscle invasive bladder cancer (MIBC) accounts for approximately $20-25 \%$ of $\mathrm{BCa}$, and is prone to metastasis and progression. ${ }^{2}$ Radical cystectomy (RC) is currently the most effective treatment for MIBC, which can maximize the survival time of patients. ${ }^{3}$ However, the 5-year tumor-specific survival rate of MIBC patients is only about $50 \%{ }^{4}$

The identification and discovery of tumor biomarkers are related to the risk assessment, treatment plan and prognosis of patients with $\mathrm{BCa}$. Several biomarkers and biomarker combinations, such as C-reactive protein and neutrophil-lymphocyte ratio (NLR), platelet-lymphocyte ratio (PLR), systemic immune-inflammation index (SII), have been reported as independent prognostic value in patients with $\mathrm{BCa}$, but their value was still controversial. ${ }^{5-7}$ More and more evidence shown that there is a correlation between the activation of coagulation and fibrinolysis system and tumor angiogenesis, progression and metastasis. ${ }^{8,9}$ Many studies have reported 
that various factors of coagulation and fibrinolysis system, such as plasma fibrinogen and D-dimer, were abnormally expressed in cancer patients, and fibrinogen and D-dimer can be used as prognostic indicators of various malignant tumors. ${ }^{10-12}$

Previous studies have noted that preoperative plasma fibrinogen levels can be used to predict the degree of invasion and pathological stage of $\mathrm{BCa} .{ }^{13}$ In addition, preoperative plasma fibrinogen and D-dimer levels can be used as predictors of recurrence and progression in patients with non-muscle invasive bladder cancer (NMIBC). ${ }^{14}$ The purpose of this study was to determine the correlation between coagulation and fibrinolysis system factors and their combinations and postoperative prognosis in patients with RC.

\section{Patients and Methods}

\section{Patients Population}

A retrospective analysis of $\mathrm{BCa}$ patients who received $\mathrm{RC}$ in the Department of Urology of The First Affiliated Hospital of Bengbu Medical College from January 2014 to December 2019. The study was approved by the Ethics Committee of The First Affiliated Hospital of Bengbu Medical College, and all patients or their families have understood the purpose of the study and signed an informed consent form. The inclusion criteria were as follows: 1) histopathologic diagnosis of $\mathrm{BCa}$ after transurethral resection of bladder tumor (TURBT), including MIBC and high-grade T1 BCa; 2) age over 18 years. We excluded patients with other malignant tumors, preoperative chemotherapy or radiotherapy, unknown coagulation factors, and loss of follow-up data. Finally, 145 patients participated in the study.

\section{Data Collection and Follow-Up}

Patients' blood samples were collected within one week before surgery. Retrospective demographic information was collected from the patient's electronic medical records, including age $(\leq 65$ and $>65$ ), gender (male and female), diabetes (yes and no), hypertension (yes and no), cardiovascular diseases (yes and no), $\mathrm{T}$ stage (T1-2 and T3-4), N stage (N0 and N+), M stage (M0 and M1) and tumor size. TNM staging was assessed postoperatively using the American Joint Committee on Cancer Staging System (seventh Edition, 2010). Laboratory data such as platelet, D-dimer, fibrinogen, neutrophils, lymphocytes and albumin were collected. The definitions of PLR,
PDM, NLFgA and NLDA are as follows: PLR $=$ plateletlymphocyte ratio, $\mathrm{PDM}=$ platelet $\times$ D-dimer, $\mathrm{NLFgA}=$ neutrophil $\times$ fibrinogen/(lymphocyte $\times$ albumin $),$ NLDA $=$ neutrophil $\times$ D-dimer/(lymphocyte $\times$ albumin). The upper limit of normal (ULN) for platelets in our hospital is $350 \times$ $10^{9} / \mathrm{L}$. In this study, all patients were followed up after operation, and the survival status of patients was collected during each follow-up. The overall survival time (OS) is the time from the completion of the operation to the date of death, regardless of the cause of death. Disease-free survival (DFS) refers to the time for patients to survive without any signs or symptoms of cancer after operation.

\section{Statistical Analysis}

Continuous variables were represented by mean \pm standard deviation (SD), and classified variables were expressed by numbers and percentages. Pearson's $\chi 2$ test or Fisher exact test were used to test the differences of classified variables. X-tile software (version 3.6.1) was used to obtain the optimal cutoff values for tumor size, fibrinogen, PLR, PDM, NLFgA and NLDA. Receiver operating characteristic (ROC) curves were used to assess the correlation between different coagulation factors for OS and DFS, and p-values were corrected with the Bonferroni correction. The OS and DFS survival curves were drawn by Kaplan-Meier method and evaluated by Log rank test. Univariate and multivariate Cox proportional hazard regression models were used to examine the potential risk factors associated with OS and DFS, and the corresponding hazard ratios (HRs) and 95\% confidence interval (CI) were calculated. Based on the results of multivariate logistic regression, the $\mathrm{R}$ software was used to construct the nomogram, and the ROC curve and decision curve analysis (DCA) curve were used to evaluate the prediction performance of the nomogram. All statistical analyses were performed using MedCalc software (version 15.2.0) and R software (version 3.5.3). P-value $<0.05$ was considered to be statistically.

\section{Results}

\section{Baseline Demographic and Clinicopathological Characteristics}

The optimal cutoff values for tumor size, fibrinogen, PLR, PDM, NLFgA and NLDA were $4.7 \mathrm{~cm}, 3.14 \mathrm{~g} / \mathrm{L}, 154.62$, 244.86, 0.22 and 0.06 , respectively (Figure 1). Table 1 lists the demographic and clinicopathological characteristics of all patients. The majority of patients were male (86.2\%), 

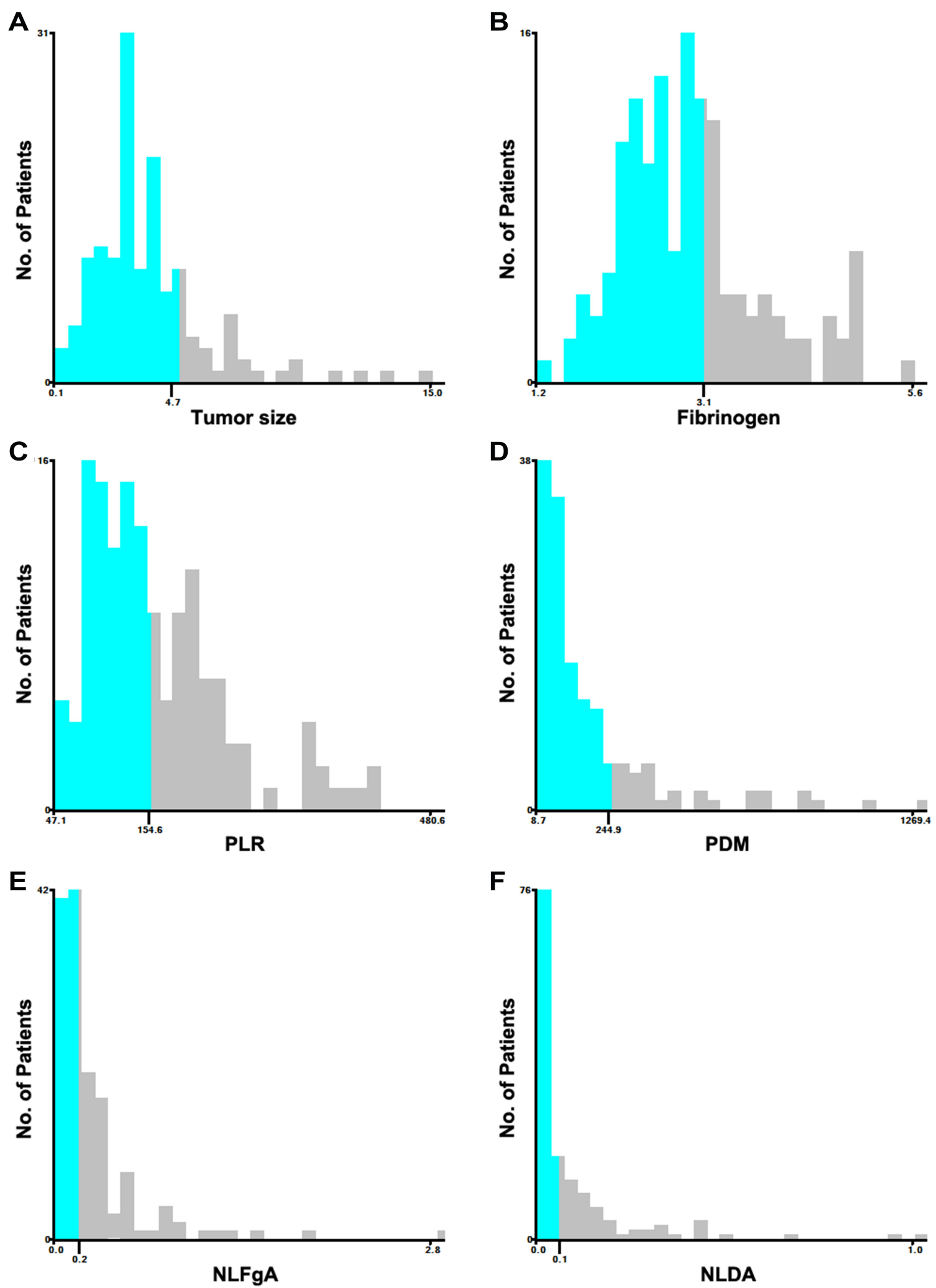

Figure I X-tile software was used to obtain the optimal cutoff values for tumor size, fibrinogen, PLR, PDM, NLFgA and NLDA. (A) Tumor size; (B) Fibrinogen; (C) Plateletlymphocyte ratio (PLR); (D) Platelet $\times$ D-dimer (PDM); (E) Neutrophil $\times$ Fibrinogen/(lymphocyte $\times$ albumin) (NLFgA); (F) Neutrophil $\times$ D-dimer/(lymphocyte $\times$ albumin) (NLDA). 
Table I Baseline Characteristics of the Study Population

\begin{tabular}{|c|c|}
\hline \multirow[t]{2}{*}{ Characteristics } & All Patients \\
\hline & No. (\%) \\
\hline Total patients & 145 \\
\hline Age, y, mean (SD) & $65.92 \pm 10.16$ \\
\hline \multicolumn{2}{|l|}{ Age categorized, y } \\
\hline$\leq 65$ & $73(50.3)$ \\
\hline$>65$ & $72(49.7)$ \\
\hline \multicolumn{2}{|l|}{ Gender } \\
\hline Male & $125(86.2)$ \\
\hline Female & $20(13.8)$ \\
\hline \multicolumn{2}{|l|}{ Diabetes } \\
\hline Yes & $21(14.5)$ \\
\hline No & $124(85.5)$ \\
\hline \multicolumn{2}{|l|}{ Hypertension } \\
\hline Yes & $52(35.9)$ \\
\hline No & $93(64.1)$ \\
\hline \multicolumn{2}{|c|}{ Cardiovascular diseases } \\
\hline Yes & $18(12.4)$ \\
\hline No & $127(87.6)$ \\
\hline \multicolumn{2}{|l|}{ T-stage } \\
\hline TI-2 & $80(55.2)$ \\
\hline T3-4 & $65(44.8)$ \\
\hline \multicolumn{2}{|l|}{$N$-stage } \\
\hline No & II 4 (78.6) \\
\hline $\mathrm{N+}$ & 31 (2I.4) \\
\hline \multicolumn{2}{|l|}{ M-stage } \\
\hline Mo & I 38 (95.2) \\
\hline MI & $7(4.8)$ \\
\hline Tumor size, cm & $3.84 \pm 2.36$ \\
\hline \multicolumn{2}{|l|}{ Platelet, I0^9/L } \\
\hline$\leq$ ULN & $127(87.6)$ \\
\hline$>$ ULN & $18(12.4)$ \\
\hline \multicolumn{2}{|l|}{ D-dimer, mg/L } \\
\hline$\leq 0.55$ & $86(59.3)$ \\
\hline$>0.55$ & $59(40.7)$ \\
\hline Fibrinogen, g/L & $2.99 \pm 0.86$ \\
\hline PLR & $165.35 \pm 83.80$ \\
\hline PDM & $186.03 \pm 225.10$ \\
\hline NLFgA & $0.32 \pm 0.36$ \\
\hline NLDA & $0.09 \pm 0.15$ \\
\hline
\end{tabular}

Abbreviations: SD, standard deviation; ULN, upper limit of normal; PLR, plateletlymphocyte ratio; PDM, platelet $\times$ D-dimer; NLFgA, neutrophil $\times$ fibrinogen/(lymphocyte $\times$ albumin); NLDA, neutrophil $\times$ D-dimer/(lymphocyte $\times$ albumin).

N0 stage $(78.6 \%)$, M0 stage $(95.2 \%)$, platelet $\leq \mathrm{ULN}$ (87.6\%), without diabetes $(85.5 \%)$, hypertension $(64.1 \%)$ and cardiovascular disease $(87.6 \%)$. In the entire cohort, the mean age of the patients was $65.92 \pm 10.16$ years, tumor size was $3.84 \pm 2.36 \mathrm{~cm}$, fibrinogen was $2.99 \pm$ $0.86 \mathrm{~g} / \mathrm{L}, \mathrm{PLR}$ was $165.35 \pm 83.80, \mathrm{PDM}$ was $186.03 \pm$ 225.10, NLFgA was $0.32 \pm 0.36$, and NLDA was 0.09 \pm 0.15 .

We evaluated the sensitivity of seven coagulationrelated indexes to the prognosis of $\mathrm{BCa}$ by ROC curve, and we found that the area under the curve (AUC) of fibrinogen was higher than platelet, D-dimer, PLR, PDM, NLFgA and NLDA in both OS (fibrinogen: $\mathrm{AUC}=0.640$, 95\% CI $=0.556-0.718 ; \mathrm{p}=0.008$ ) and DFS (fibrinogen: $\mathrm{AUC}=0.628,95 \% \mathrm{CI}=0.544-0.706 ; \mathrm{p}=0.020)$ (Table 2 and Figure 2). However, after Bonferroni correction, the p-values of all indexes have no significance.

In addition, we were divided all patients into two groups ( $\leq 3.14$ and $>3.14 \mathrm{~g} / \mathrm{L}$ ) according to the level of fibrinogen (Table 3$)$. The proportion of over $65 \mathrm{y}$ patients $(59.2 \% \mathrm{vs}$ $44.8 \%), \mathrm{N}+$ stage patients $(30.6 \%$ vs $16.7 \%), \mathrm{PDM}>244.86$ patients $(30.6 \%$ vs $17.7 \%)$, and NLDA $>0.06$ patients $(42.9 \%$ vs $33.3 \%$ ) in the fibrinogen $>3.14$ group was higher than fibrinogen $\leq 3.14$ group, but the difference observed was not statistically significant (age, $\mathrm{p}=0.101 ; \mathrm{N}$-stage, $\mathrm{p}=0.053$; PDM, $\mathrm{p}=0.076$; NLDA, $\mathrm{p}=0.260$ ). Compared with fibrinogen $\leq 3.14$ patients, patients in the fibrinogen $>3.14$ group were female $(24.5 \%$ vs $8.3 \% ; \mathrm{p}=0.008)$, larger tumor size $(>4.7 \mathrm{~cm}$ : $36.7 \%$ vs $16.7 \%$; $\mathrm{p}=0.007$ ), higher T stage (T3-4: 61.2\% vs $36.5 \% ; \mathrm{p}=0.005)$, M stage (M1: $10.2 \%$ vs $2.1 \% ; \mathrm{p}=0.031)$, platelet (>ULN: $20.4 \%$ vs $8.3 \% ; p=0.037)$, D-dimer $(>0.55$ : $53.1 \%$ vs $34.4 \%$; $\mathrm{p}=0.030)$, PLR $(>154.62$ : $55.1 \%$ vs $36.5 \%$; $\mathrm{p}=0.032)$ and NLFgA $(>0.22: 73.5 \%$ vs $31.3 \%$; $<0.001)$.

\section{Identification of Prognostic Factors of OS and DFS}

We used univariate and multivariate Cox proportional hazard regression models to determine the factor affecting the survival of patients with $\mathrm{BCa}$. Univariate Cox regression analysis showed that $\mathrm{T}$ stage, $\mathrm{N}$ stage, $\mathrm{M}$ stage, tumor size, fibrinogen (Figure 3), PDM, NLFgA and NLDA were related factors of OS in patients with RC (Table 4), PLR and the above factors were related factors of DFS (Table 5). After the above variables were included in multivariate Cox regression analysis, $\mathrm{T}$ stage, $\mathrm{N}$ stage, $\mathrm{M}$ stage and fibrinogen were still independent risk factors for OS and DFS in patients with BCa. Moreover, fibrinogen $>3.14$ patients had worse OS (HR, 2.58, 95\% CI = 1.28-5.23; p = 0.008) and DFS (HR, 2.60, 95\% CI $=1.20-5.65 ; \mathrm{p}=0.016$ ) compared with fibrinogen $\leq 3.14$ patients in multivariate Cox analysis. 
Table 2 Analysis of Predictive Accuracy Through the Evaluation of the Area Under the Curve (AUC)

\begin{tabular}{|l|l|l|l|l|l|l|}
\hline \multirow{2}{*}{ Characteristics } & \multicolumn{2}{l|}{ Overall Survival } & \multicolumn{2}{l|}{ Disease-Free Survival } \\
\cline { 2 - 7 } & AUC & $\mathbf{9 5 \%} \mathbf{~ C l}$ & $\mathbf{P}$ value & AUC & $\mathbf{9 5 \%} \mathbf{~ C l}$ & $\mathbf{P}$ value \\
\hline Platelet & 0.522 & $0.438-0.606$ & 0.675 & 0.531 & $0.446-0.614$ & 0.576 \\
D-dimer & 0.541 & $0.457-0.624$ & 0.432 & 0.527 & $0.443-0.611$ & 0.616 \\
Fibrinogen & 0.640 & $0.556-0.718$ & $\mathbf{0 . 0 0 8}$ & 0.628 & $0.544-0.706$ & $\mathbf{0 . 0 2 0}$ \\
PLR & 0.560 & $0.475-0.642$ & 0.257 & 0.585 & $0.500-0.666$ & 0.121 \\
PDM & 0.558 & $0.473-0.640$ & 0.271 & 0.547 & $0.462-0.629$ & 0.394 \\
NLFgA & 0.606 & $0.522-0.686$ & $\mathbf{0 . 0 4 4}$ & 0.584 & $0.499-0.665$ & 0.125 \\
NLDA & 0.587 & $0.503-0.668$ & 0.097 & 0.573 & $0.489-0.655$ & 0.180 \\
\hline
\end{tabular}

Note: $P$-value $<0.05$ are shown in bold.

Abbreviations: AUC, area under the curve; Cl, confidence interval; PLR, platelet-lymphocyte ratio; PDM, platelet $\times$ D-dimer; NLFgA, neutrophil $\times$ fibrinogen/(lymphocyte $\times$ albumin); NLDA, neutrophil $\times$ D-dimer/(lymphocyte $\times$ albumin).

\section{Establishment and Verification of}

\section{Prognostic Nomograms for OS and CSS}

Based on the results of multivariate Cox regression analysis, we constructed OS and DFS nomograms based on $\mathrm{N}$ stage, $\mathrm{M}$ stage, tumor size and fibrinogen to predict the 1-year and 3-year survival rates of RC patients (Figure 4). Each subtype of the variables on the nomogram corresponds to a point on the "Point" scale. By adding the scores associated with each variable and projecting the "Total point" to the lowest number, the probabilities of OS and DFS for 1-year and 3-years can be estimated.
A

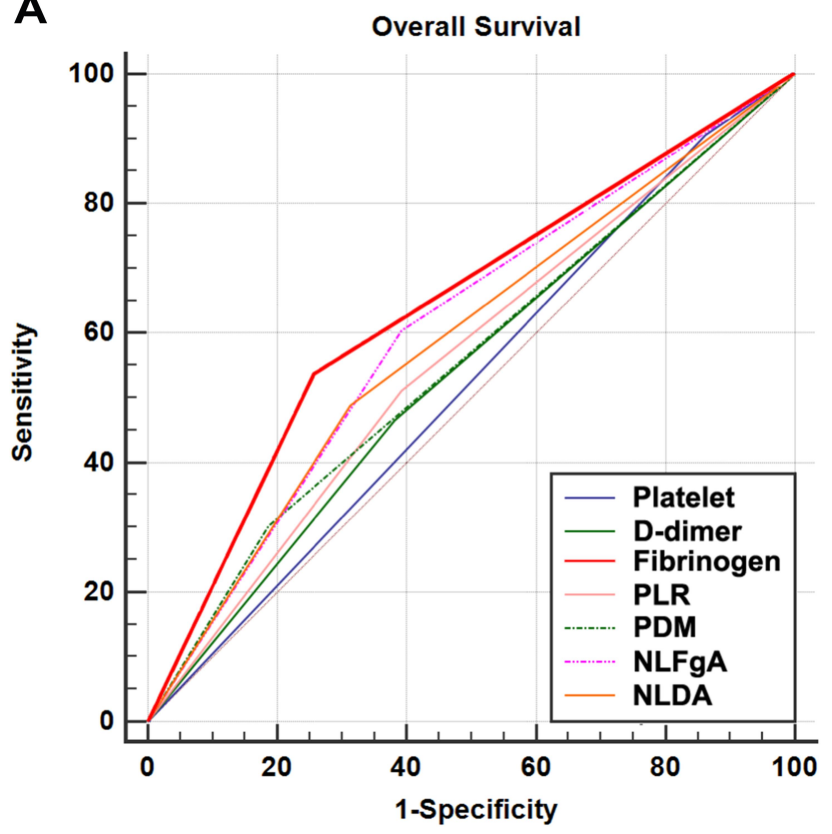

Analysis of the time-dependent ROC curves across the entire cohort showed that the AUC of the nomogram used to predict OS and DFS were $0.741(95 \% \mathrm{CI}=0.662-$ $0.810 ; \mathrm{p}<0.001)$ and $0.733(95 \% \mathrm{CI}=0.653-0.803 ; \mathrm{p}<$ 0.001 ), respectively (Figure $5 \mathrm{~A}$ and $\mathrm{B}$ ). In addition, DCA curves also shows better clinical utility of the nomogram (Figure 5C and D).

\section{Discussion}

In this study, we collected clinical and laboratory data from patients and studied the effect of coagulation and
B

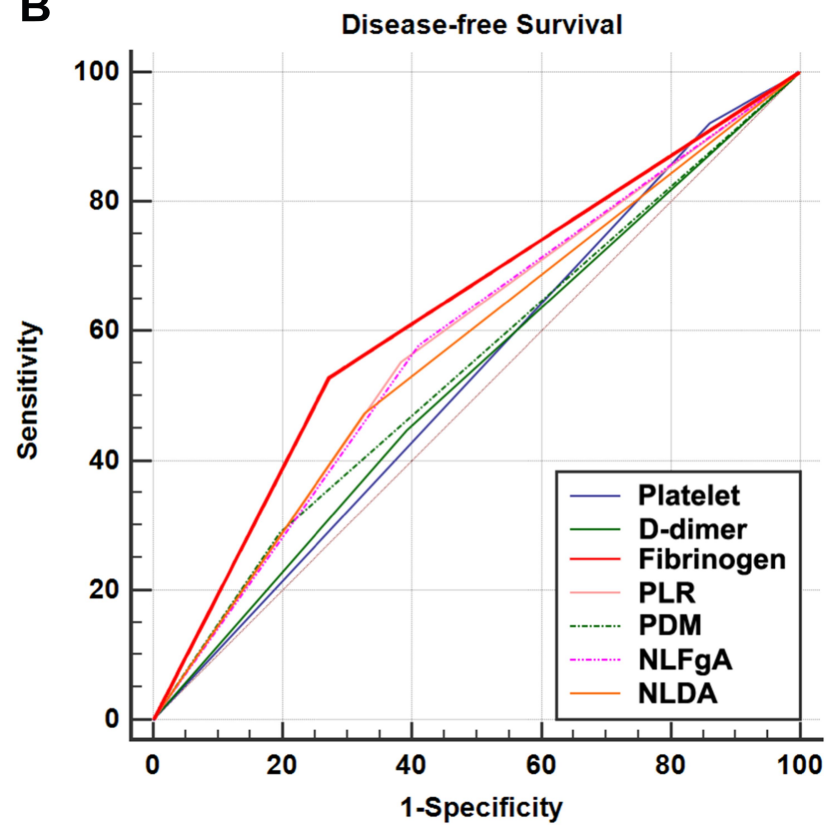

Figure 2 Analysis of predictive accuracy through the evaluation of the area under the curve (AUC). (A) Overall survival (OS); (B) Disease-free survival (DFS). PLR, plateletlymphocyte ratio; PDM, platelet $\times$ D-dimer; NLFgA, neutrophil $\times$ Fibrinogen/(lymphocyte $\times$ albumin); NLDA, neutrophil $\times$ D-dimer/(lymphocyte $\times$ albumin). 
Table 3 Baseline Characteristics of All Patients When Using Fibrinogen as an Assessment Tool

\begin{tabular}{|c|c|c|c|c|}
\hline \multirow[t]{2}{*}{ Characteristics } & \multirow{2}{*}{$\begin{array}{l}\text { All Patients } \\
\text { No. (\%) }\end{array}$} & \multirow{2}{*}{$\frac{\leq 3.14 \mathrm{~g} / \mathrm{L}}{\text { No. (\%) }}$} & \multirow{2}{*}{$\frac{>3.14 \mathrm{~g} / \mathrm{L}}{\text { No. (\%) }}$} & \multirow[t]{2}{*}{$\mathbf{P}$} \\
\hline & & & & \\
\hline Total patients & 145 & $96(66.2)$ & $49(33.8)$ & \\
\hline Age categorized, y & & & & 0.101 \\
\hline$\leq 65$ & $73(50.3)$ & $53(55.2)$ & $20(40.8)$ & \\
\hline$>65$ & $72(49.7)$ & $43(44.8)$ & $29(59.2)$ & \\
\hline Gender & & & & 0.008 \\
\hline Male & $125(86.2)$ & $88(91.7)$ & $37(75.5)$ & \\
\hline Female & $20(13.8)$ & $8(8.3)$ & $12(24.5)$ & \\
\hline Diabetes & & & & 0.342 \\
\hline Yes & $21(14.5)$ & $12(12.5)$ & $9(18.4)$ & \\
\hline No & $124(85.5)$ & $84(87.5)$ & $40(81.6)$ & \\
\hline Hypertension & & & & 0.876 \\
\hline Yes & $52(35.9)$ & $34(35.4)$ & $18(36.7)$ & \\
\hline No & $93(64.1)$ & $62(64.6)$ & $31(63.3)$ & \\
\hline Cardiovascular diseases & & & & 0.564 \\
\hline Yes & $18(12.4)$ & $13(13.5)$ & $5(10.2)$ & \\
\hline No & $127(87.6)$ & $83(86.5)$ & $44(89.8)$ & \\
\hline T-stage & & & & 0.005 \\
\hline TI-2 & $80(55.2)$ & $61(63.5)$ & $19(38.8)$ & \\
\hline T3-4 & $65(44.8)$ & $35(36.5)$ & $30(61.2)$ & \\
\hline $\mathrm{N}$-stage & & & & 0.053 \\
\hline No & II4 (78.6) & $80(83.3)$ & $34(69.4)$ & \\
\hline $\mathrm{N}+$ & $31(21.4)$ & $16(16.7)$ & $15(30.6)$ & \\
\hline M-stage & & & & 0.031 \\
\hline Mo & $138(95.2)$ & $94(97.9)$ & $44(89.8)$ & \\
\hline MI & $7(4.8)$ & $2(2.1)$ & $5(10.2)$ & \\
\hline Tumor size, $\mathrm{cm}$ & & & & 0.007 \\
\hline$\leq 4.7$ & III (76.6) & $80(83.3)$ & $31(63.3)$ & \\
\hline$>4.7$ & $34(23.4)$ & $16(16.7)$ & I8 (36.7) & \\
\hline Platelet, I0^9/L & & & & 0.037 \\
\hline$\leq \mathrm{ULN}$ & $127(87.6)$ & 88 (91.7) & $39(79.6)$ & \\
\hline$>$ ULN & $18(12.4)$ & $8(8.3)$ & $10(20.4)$ & \\
\hline D-dimer, mg/L & & & & 0.030 \\
\hline$\leq 0.55$ & $86(59.3)$ & $63(65.6)$ & $23(46.9)$ & \\
\hline$>0.55$ & $59(40.7)$ & $33(34.4)$ & $26(53.1)$ & \\
\hline PLR & & & & 0.032 \\
\hline$\leq 154.62$ & $83(57.2)$ & $61(63.5)$ & $22(44.9)$ & \\
\hline$>154.62$ & $62(42.8)$ & $35(36.5)$ & $27(55.1)$ & \\
\hline PDM & & & & 0.076 \\
\hline$\leq 244.86$ & II 13 (77.9) & $79(82.3)$ & $34(69.4)$ & \\
\hline$>244.86$ & $32(22.1)$ & $17(17.7)$ & $15(30.6)$ & \\
\hline $\mathrm{NLFgA}$ & & & & $<0.001$ \\
\hline$\leq 0.22$ & $79(54.5)$ & $66(68.8)$ & $13(26.5)$ & \\
\hline
\end{tabular}

(Continued) 
Table 3 (Continued).

\begin{tabular}{|l|l|l|l|}
\hline \multirow{2}{*}{ Characteristics } & All Patients & $\leq 3.14 \mathbf{g} / \mathbf{L}$ & $\mathbf{3 . 1 4} \mathbf{g} / \mathbf{L}$ \\
\cline { 2 - 5 } & No. (\%) & No. (\%) & No. (\%) \\
\hline$>0.22$ & $66(45.5)$ & $30(31.3)$ & $36(73.5)$ \\
\hline NLDA & & & \\
$\leq 0.06$ & $92(63.4)$ & $64(66.7)$ & $28(57.1)$ \\
$>0.06$ & $53(36.6)$ & $32(33.3)$ & $21(42.9)$ \\
\hline
\end{tabular}

Note: $P$-value $<0.05$ are shown in bold.

Abbreviations: ULN, upper limit of normal; PLR, platelet-lymphocyte ratio; PDM, platelet $\times$ D-dimer; NLFgA, neutrophil $\times$ fibrinogen/(lymphocyte $\times$ albumin); NLDA, neutrophil $\times$ D-dimer/(lymphocyte $\times$ albumin).

fibrinolysis system factors on postoperative survival of RC patients. Multivariate Cox regression analysis showed that preoperative plasma fibrinogen was an independent risk factor for the prognosis of $\mathrm{BCa}$ patients treated with $\mathrm{RC}$. Our study found that preoperative plasma fibrinogen can be used as an independent predictor of OS and DFS in patients with RC, and fibrinogen is a better predictor of prognosis than platelet, D-dimer, PLR, PDM, NLFgA and NLDA. In addition, the nomogram based on plasma fibrinogen has better accuracy and discrimination.

Most malignant tumor patients have obvious hypercoagulable state in the blood, which is closely related to the occurrence, development, recurrence and metastasis of tumor. ${ }^{15}$ Many studies have shown that tumor cells can secrete procoagulant active substances, such as tissue factor procoagulant activity (TF-PCA). ${ }^{16}$ In addition, the destruction of tissues by cancer cells can also release tissue factors and activate the coagulation process, making cancer patients more prone to hypercoagulable state. ${ }^{17}$ Hypercoagulable state can not only promote thrombosis

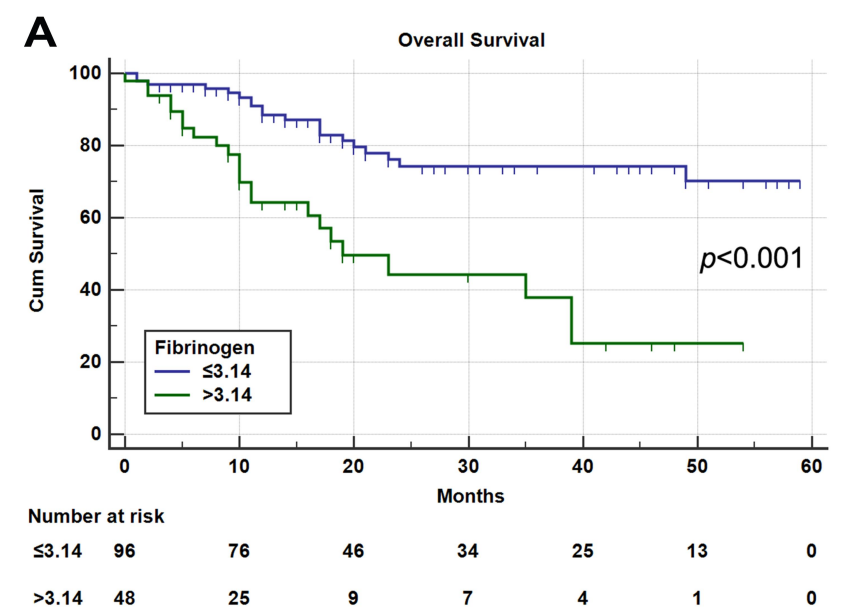

and lead to thromboembolic disease, but also slow blood flow during hypercoagulation, and tumor cells are not affected by the shear stress. Instead, hypercoagulable state can promote tumor cells to form cancer thrombus, adhere to platelets or endothelium with the aid of fibrinogen adhesion, and promote tumor metastasis. ${ }^{18}$ The increased fibrinogen content aggravates the hypercoagulable state, and fibrinogen protects tumor cells from being killed by antibodies, chemotherapy and other drugs to some extent. ${ }^{19,20}$

Fibrinogen, also known as human coagulation factor I, with a molecular weight of $340 \mathrm{kDa}$. It is mainly synthesized by liver parenchyma cells and is one of the main components of plasma proteins. ${ }^{21}$ Fibrinogen is about 2-4 $\mathrm{g} / \mathrm{L}$ in normal human plasma, which is one of the central proteins in the coagulation system and the final substrate activated by coagulation factors in the process of coagulation, which can not only play the function of hemostasis and coagulation, but also mediate platelet aggregation and affect blood viscosity. ${ }^{22}$

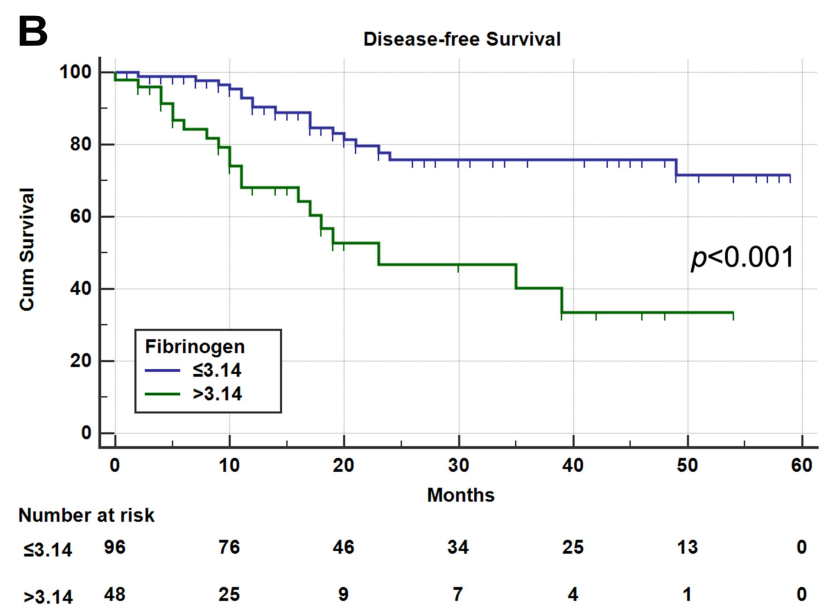

Figure 3 Kaplan-Meier curves of survival based on plasma fibrinogen value of 145 BCa patients. (A) Overall survival (OS); (B) Disease-free survival (DFS). 
Table 4 Univariate and Multivariate Analyses of Factors Associated with Overall Survival (OS)

\begin{tabular}{|c|c|c|c|c|c|}
\hline \multirow[t]{2}{*}{ Characteristics } & \multirow[t]{2}{*}{ Category or Characteristics } & \multicolumn{2}{|c|}{ Univariate Analyses } & \multicolumn{2}{|c|}{ Multivariate Analyses } \\
\hline & & HR (95\% Cl) & $P$ value & HR (95\% Cl) & $P$ value \\
\hline Age & $>65 / \leq 65$ & $1.28(0.70-2.34)$ & 0.425 & & \\
\hline Gender & Female/Male & $1.26(0.56-2.84)$ & 0.582 & & \\
\hline Diabetes & No/Yes & $0.55(0.26-1.14)$ & 0.107 & & \\
\hline Hypertension & No/Yes & $0.93(0.49-1.77)$ & 0.832 & & \\
\hline Cardiovascular diseases & No/Yes & $0.74(0.29-1.89)$ & 0.530 & & \\
\hline T-stage & $\mathrm{T} 3-4 / \mathrm{TI}-2$ & $3.66(1.88-7.13)$ & $<0.001$ & $1.59(0.73-3.45)$ & 0.239 \\
\hline $\mathrm{N}$-stage & $\mathrm{N}+/ \mathrm{N} 0$ & $4.26(2.32-7.82)$ & $<0.001$ & $2.72(1.34-5.53)$ & 0.006 \\
\hline M-stage & $\mathrm{MI} / \mathrm{MO}$ & $5.64(1.96-16.19)$ & 0.001 & $3.46(1.03-11.66)$ & 0.045 \\
\hline Tumor size, $\mathrm{cm}$ & $>4.7 / \leq 4.7$ & $3.51(1.86-6.62)$ & $<0.001$ & $2.49(1.18-5.26)$ & 0.017 \\
\hline Platelet, I0^9/L & $>\mathrm{ULN} / \leq \mathrm{ULN}$ & $0.87(0.31-2.44)$ & 0.789 & & \\
\hline D-dimer, mg/L & $>0.55 / \leq 0.55$ & I.44 (0.79-2.63) & 0.232 & & \\
\hline Fibrinogen, $g / L$ & $>3.14 / \leq 3.14$ & $3.57(1.94-6.56)$ & $<0.001$ & $2.58(1.28-5.23)$ & 0.008 \\
\hline PLR & $>154.62 / \leq 154.62$ & $1.75(0.96-3.19)$ & 0.068 & & \\
\hline PDM & $>244.86 / \leq 244.86$ & $2.19(1.14-4.22)$ & 0.019 & $1.27(0.56-2.90)$ & 0.568 \\
\hline NLFgA & $>0.22 / \leq 0.22$ & $2.49(1.34-4.60)$ & 0.004 & $1.17(0.54-2.53)$ & 0.694 \\
\hline NLDA & $>0.06 / \leq 0.06$ & $2.02(1.11-3.67)$ & 0.022 & $1.00(0.47-2.16)$ & 0.997 \\
\hline
\end{tabular}

Note: $P$-value $<0.05$ are shown in bold.

Abbreviations: OS, overall survival; HR, hazard ratio; Cl, confidence interval; ULN, upper limit of normal; PLR, platelet-lymphocyte ratio; PDM, platelet $\times$ D-dimer; NLFgA, neutrophil $\times$ fibrinogen/(lymphocyte $\times$ albumin); NLDA, neutrophil $\times$ D-dimer/(lymphocyte $\times$ albumin).

Table 5 Univariate and Multivariate Analyses of Factors Associated with Disease-Free Survival (DFS)

\begin{tabular}{|c|c|c|c|c|c|}
\hline \multirow[t]{2}{*}{ Characteristics } & \multirow[t]{2}{*}{ Category or Characteristics } & \multicolumn{2}{|c|}{ Univariate Analyses } & \multicolumn{2}{|c|}{ Multivariate Analyses } \\
\hline & & HR $(95 \% \mathrm{CI})$ & $P$ value & HR $(95 \% \mathrm{CI})$ & $P$ value \\
\hline Age & $>65 / \leq 65$ & $1.22(0.64-2.32)$ & 0.538 & & \\
\hline Gender & Female/Male & $1.23(0.5 \mathrm{I}-2.96)$ & 0.637 & & \\
\hline Diabetes & No/Yes & $0.64(0.28-1.45)$ & 0.282 & & \\
\hline Hypertension & No/Yes & $0.90(0.45-1.78)$ & 0.761 & & \\
\hline Cardiovascular diseases & No/Yes & $0.84(0.33-2.16)$ & 0.722 & & \\
\hline T-stage & $\mathrm{T} 3-4 / \mathrm{TI}-2$ & $4.62(2.19-9.77)$ & $<0.001$ & $2.02(0.85-4.80)$ & 0.113 \\
\hline $\mathrm{N}$-stage & $\mathrm{N}+/ \mathrm{N} 0$ & $4.43(2.32-8.44)$ & $<0.001$ & $2.72(1.24-6.01)$ & 0.013 \\
\hline M-stage & $\mathrm{MI} / \mathrm{MO}$ & $7.09(2.46-20.48)$ & $<0.001$ & $6.28(1.69-23.29)$ & 0.006 \\
\hline Tumor size, cm & $>4.7 / \leq 4.7$ & $4.03(2.07-7.86)$ & $<0.001$ & $3.19(1.44-7.05)$ & 0.004 \\
\hline Platelet, I0^9/L & $>\mathrm{ULN} / \leq \mathrm{ULN}$ & $0.73(0.22-2.37)$ & 0.596 & & \\
\hline D-dimer, mg/L & $>0.55 / \leq 0.55$ & $1.36(0.72-2.58)$ & 0.345 & & \\
\hline Fibrinogen, g/L & $>3.14 / \leq 3.14$ & $3.56(1.86-6.79)$ & $<0.001$ & $2.60(1.20-5.65)$ & 0.016 \\
\hline PLR & $>154.62 / \leq 154.62$ & $2.08(1.10-3.96)$ & 0.025 & I.33 $(0.56-3.20)$ & 0.520 \\
\hline PDM & $>244.86 / \leq 244.86$ & $2.11(1.04-4.26)$ & 0.038 & I. $18(0.48-2.90)$ & 0.711 \\
\hline NLFgA & $>0.22 / \leq 0.22$ & $2.27(1.19-4.33)$ & 0.013 & $0.89(0.36-2.22)$ & 0.805 \\
\hline NLDA & $>0.06 / \leq 0.06$ & $1.91(1.01-3.62)$ & 0.047 & $0.89(0.39-2.05)$ & 0.786 \\
\hline
\end{tabular}

Note: $P$-value $<0.05$ are shown in bold.

Abbreviations: DFS, disease-free survival; HR, hazard ratio; Cl, confidence interval; ULN, upper limit of normal; PLR, platelet-lymphocyte ratio; PDM, platelet $\times$ D-dimer; NLFgA, neutrophil $\times$ fibrinogen/(lymphocyte $\times$ albumin); NLDA, neutrophil $\times$ D-dimer/(lymphocyte $\times$ albumin).

In addition to the important role of fibrinogen in the coagulation pathway, fibrinogen is also involved in inflammation and cancer progression. Fibrinogen can act as a bridge between different adhesion molecules, increase the adhesion between leukocytes, platelets and tumor cells, and play an important role in tumor metastasis. ${ }^{23}$ Elevated plasma fibrinogen levels have been shown to be a poor prognostic indicator for prostate cancer, renal cell 
A

Points

$\mathrm{N}$ stage

M stage

Tumor size, cm

Fibrinogen, g/L

Total Point

1-year survival

3-year survival

B

Points

$\mathrm{N}$ stage

M stage

Tumor size, cm

Fibrinogen, g/L

Total Point

1-year survival

3-year survival

\section{Overall Survival}

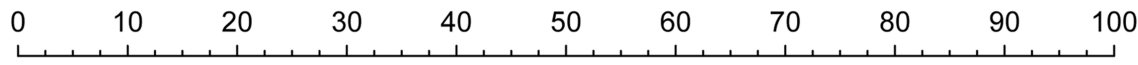

$\mathrm{N}+$

NO

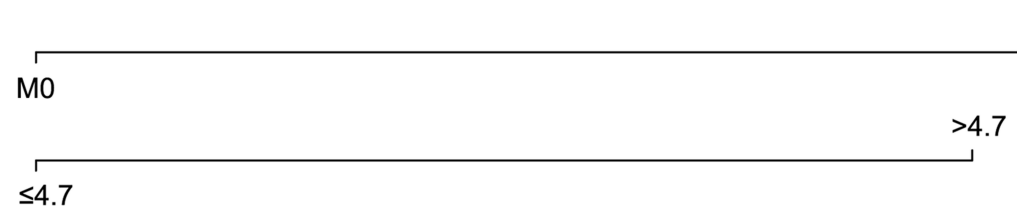

$>3.14$

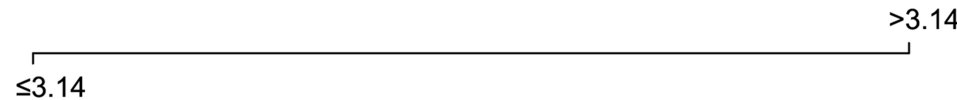

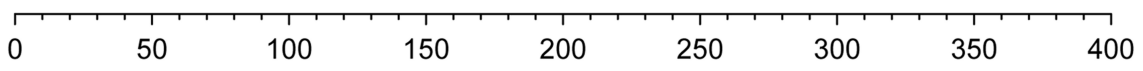
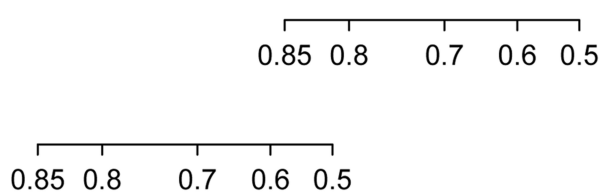

Disease-free Survival
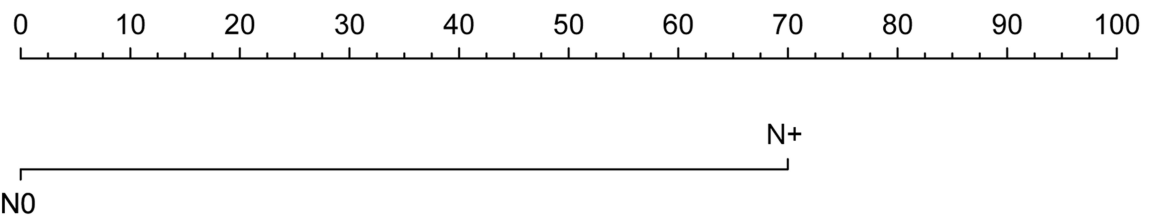

NO

M1

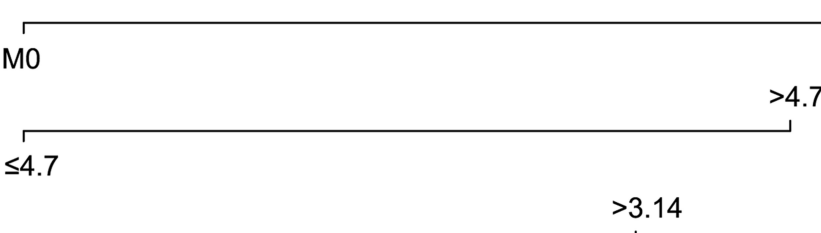

$\leq 3.14$
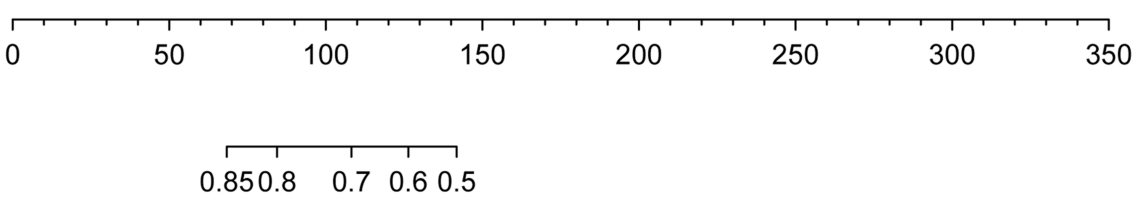

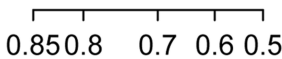

Figure 4 Nomogram predicting I-, and 3-year overall survival (OS) and disease-free survival (DFS) rate of BCa patients. (A) OS rate; (B) CSS rate. 

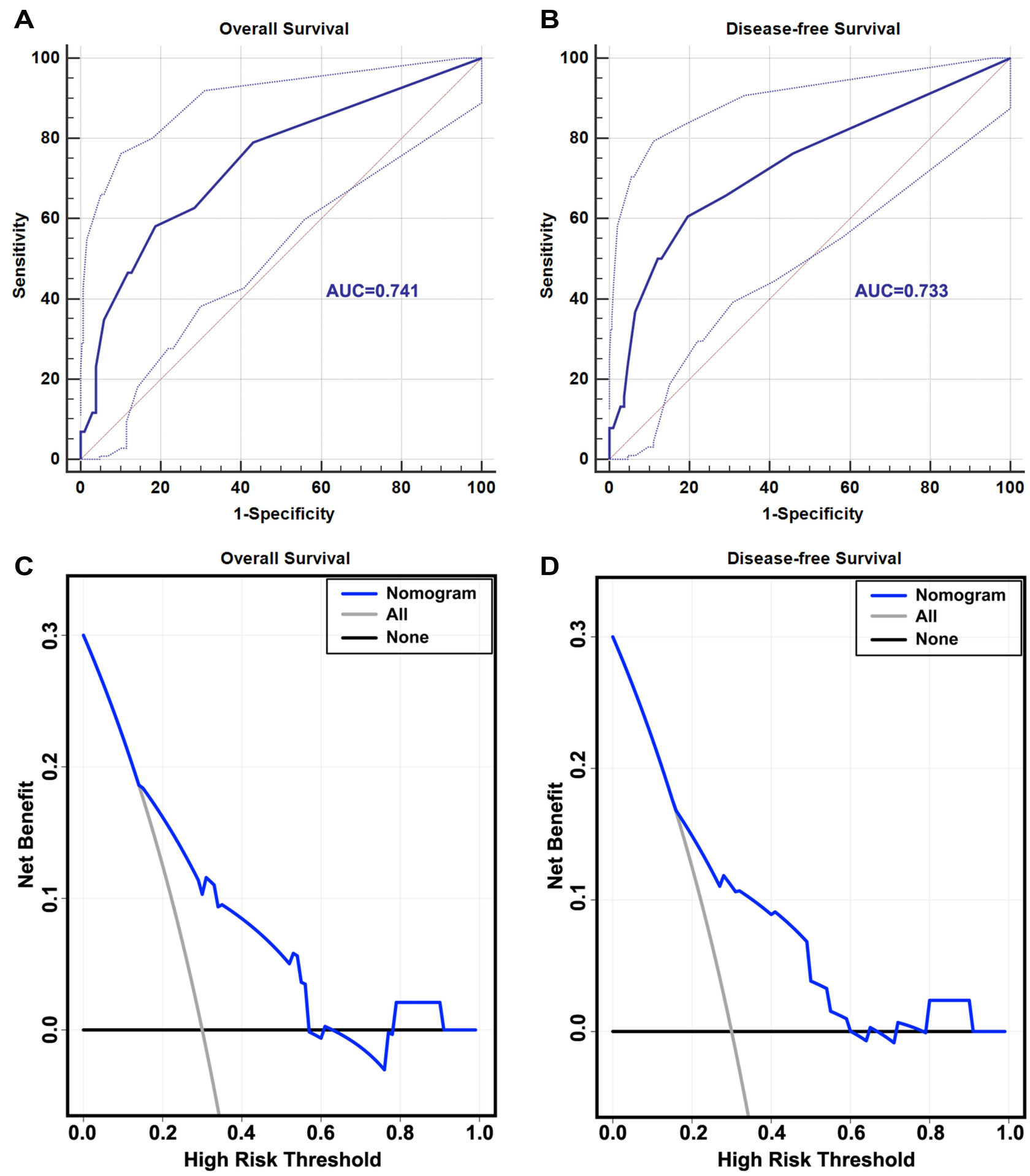

Figure 5 Receiver operating characteristic (ROC) curves and decision curve analysis (DCA) curves detects the predictive value of the nomograms. (A) ROC curve for overall survival (OS). (B) ROC curve for disease-free survival (DFS); (C) DCA curve for OS. (D) DCA curve for DFS.

carcinoma and upper urothelial carcinoma. ${ }^{24}$ And studies have shown that plasma fibrinogen greater than $3.295 \mathrm{~g} / \mathrm{L}$ was an independent prognostic factor for early death in patients with robot-assisted RC. ${ }^{25}$ Our study found that plasma fibrinogen can be used as an independent risk factor for OS and CSS in BCa patients treated with RC.

We also found an interesting finding. It is well known that women with $\mathrm{BCa}$ have a poorer prognosis than men, but the 
exact mechanism is still unknown. ${ }^{26,27}$ In our study, the proportion of female patients in the high-fibrinogen group was much higher than in the low-fibrinogen group, which may also be a reason for the poor prognosis of female patients.

Nomogram plays an important role in predicting the prognosis and individualized treatment of patients. It has been widely used in urinary malignant tumors such as bladder cancer, ${ }^{28,29}$ prostate cancer, ${ }^{30}$ and renal cell carcinoma. ${ }^{31}$ In our study, we constructed a nomogram of fibrinogen based on the results of multivariate Cox regression analysis, which can accurately predict OS and DFS of BCa patients after RC. For the patients with high preoperative fibrinogen and large tumor size before surgery, early adjuvant chemotherapy is recommended to improve the survival time.

In this study, we investigated the effect of coagulation and fibrinolysis system factors on the prognosis of RC patients, and found that plasma fibrinogen is the effect of OS and DFS in BCa patients after RC. However, this study also has some limitations. This study is a single-center retrospective study, which needs to expand the sample to conduct a multicenter prospective study. Moreover, we do not include postoperative complications, which will also affect the prognosis of patients.

\section{Conclusions}

In summary, we observed that plasma fibrinogen can be used as an independent predictor of OS and DFS in BCa patients with $\mathrm{RC}$, and the nomogram based on plasma fibrinogen can guide the individualized treatment plan for $\mathrm{BCa}$ patients, and further assessment of the patients' systemic condition is needed before the application of the nomogram to clinical practice.

\section{Abbreviations}

$\mathrm{BCa}$, bladder cancer; MIBC, muscle invasive bladder cancer; NMIBC, non-muscle invasive bladder cancer; RC, radical cystectomy; PLR, platelet-lymphocyte ratio; PDM, platelet $\times$ D-dimer; NLFgA, neutrophil $\times$ fibrinogen/(lymphocyte $\times$ albumin); NLDA, neutrophil $\times$ D-dimer/(lymphocyte $\times$ albumin); ULN, upper limit of normal; OS, overall survival; DFS, disease-free survival; $\mathrm{SD}$, standard deviation; HRs, hazard ratios; CI, confidence interval; ROC, receiver operating characteristic; DCA, decision curve analysis; AUC, area under the curve.

\section{Data Sharing Statement}

The dataset used during the study are available from the corresponding author on a reasonable request.

\section{Ethics Approval and Consent to Participate}

The study was in line with the Helsinki Declaration and approved by the Ethics Committee of The First Affiliated Hospital of Bengbu Medical College (V.20190909001). The study outcomes will not affect the future management of the patients. The use of human blood samples was in accordance with the legislation in China. Informed consent was obtained from the controls and patients or their relatives.

\section{Author Contributions}

All authors made a significant contribution to the work reported, whether that is in the conception, study design, execution, acquisition of data, analysis and interpretation, or in all these areas; took part in drafting, revising or critically reviewing the article; gave final approval of the version to be published; have agreed on the journal to which the article has been submitted; and agree to be accountable for all aspects of the work.

\section{Funding}

This work was supported by the Key Projects of Natural Science Foundation of Colleges and Universities in Anhui Province [grant numbers KJ2019A0355], Science Foundation of Bengbu Medical College [grant numbers BYKY1840ZD] and Natural Science Foundation of Anhui Province [grant numbers 2008085QH358].

\section{Disclosure}

We declare that there are no conflicts of interest in this work.

\section{References}

1. Siegel RL, Miller KD, Jemal A. Cancer statistics, 2020. CA Cancer J Clin. 2020;70(1):7-30. doi:10.3322/caac.21590

2. Mao W, Huang X, Wang L, et al. Circular RNA hsa_circ_0068871 regulates FGFR3 expression and activates STAT3 by targeting miR-181a-5p to promote bladder cancer progression. J Exp Clin Cancer Res. 2019;38(1):169. doi:10.1186/s13046-019-1136-9

3. Stein JP, Lieskovsky G, Cote R, et al. Radical cystectomy in the treatment of invasive bladder cancer: long-term results in 1054 patients. J Clin Oncol. 2001;19(3):666-675. doi:10.1200/JCO.2001. 19.3.666

4. Marcos-Gragera R, Mallone S, Kiemeney LA, et al. Urinary tract cancer survival in Europe 1999-2007: results of the population-based study EUROCARE-5. Eur J Cancer. 2015;51(15):2217-2230. doi:10. 1016/j.ejca.2015.07.028 
5. Kaynar M, Yildirim ME, Badem H, et al. Bladder cancer invasion predictability based on preoperative neutrophil-lymphocyte ratio. Tumor Biol. 2014;35(7):6601-6605. doi:10.1007/s13277-014-1889-x

6. Guo YD, Cai KK, Mao SY, et al. Preoperative C-reactive protein/ albumin ratio is a significant predictor of survival in bladder cancer patients after radical cystectomy: a retrospective study. Cancer Manag Res. 2018;10:4789-4804. doi:10.2147/CMAR.S180301

7. Zhang WT, Wang RL, Ma WC, et al. Systemic immune-inflammation index predicts prognosis of bladder cancer patients after radical cystectomy. Ann Transl Med. 2019;7(18).

8. Palumbo JS, Kombrinck KW, Drew AF, et al. Fibrinogen is an important determinant of the metastatic potential of circulating tumor cells. Blood. 2000;96(10):3302-3309. doi:10.1182/blood. V96.10.3302

9. Kvolik S, Jukic M, Matijevic M, Marjanovic K, Glavas-Obrovac L. An overview of coagulation disorders in cancer patients. Surg Oncol. 2010;19(1):E33-E46. doi:10.1016/j.suronc.2009.03.008

10. Zhu LR, Li J, Chen P, Jiang Q, Tang XP. Clinical significance of plasma fibrinogen and D-dimer in predicting the chemotherapy efficacy and prognosis for small cell lung cancer patients. Clin Transl Oncol. 2016;18(2):178-188. doi:10.1007/s12094-015-1350-7

11. Dirix LY, Salgado R, Weytjens R, et al. Plasma fibrin D-dimer levels correlate with tumour volume, progression rate and survival in patients with metastatic breast cancer. Br J Cancer. 2002;86 (3):389-395. doi:10.1038/sj.bjc.6600069

12. Blackwell K, Hurwitz H, Lieberman G, et al. Circulating D-dimer levels are better predictors of overall survival and disease progression than carcinoembryonic antigen levels in patients with metastatic colorectal carcinoma. Cancer. 2004;101(1):77-82. doi:10.1002/ cncr. 20336

13. Ma CQ, Lu BX, Diao CW, et al. Preoperative neutrophil-lymphocyte ratio and fibrinogen level in patients distinguish between muscle-invasive bladder cancer and non-muscle-invasive bladder cancer. Onco Targets Ther. 2016;9:4917-4922. doi:10.2147/OTT. $\mathrm{S} 107445$

14. Liu JK, Li DW, Cao L, et al. Elevated preoperative plasma fibrinogen level is an independent predictor of malignancy and advanced stage disease in patients with bladder urothelial tumors. Int J Surg. 2016;36:249-254. doi:10.1016/j.ijsu.2016.11.010

15. Caine GJ, Stonelake PS, Lip GY, Kehoe ST. The hypercoagulable state of malignancy: pathogenesis and current debate. Neoplasia. 2002;4(6):465-473. doi:10.1038/sj.neo.7900263

16. Lawrence SO, Simpson-Haidaris PJ. Regulated de novo biosynthesis of fibrinogen in extrahepatic epithelial cells in response to inflammation. Thromb Haemost. 2004;92(2):234-243. doi:10.1160/ TH04-01-0024
17. Jurianz K, Ziegler S, Garcia-Schuler H, et al. Complement resistance of tumor cells: basal and induced mechanisms. Mol Immunol. 1999;36(13-14):929-939. doi:10.1016/S0161-5890(99)00115-7

18. Elliott BD, Copley AL. The biorheology of tumor cells. Biorheology. 1984;21(1-2):85-91.

19. Battinelli EM, Ansell J. Cancer and thrombosis. Curr Hepatol Rep. 2005;4(5):378-384.

20. Zheng S, Shen J, Jiao Y, et al. Platelets and fibrinogen facilitate each other in protecting tumor cells from natural killer cytotoxicity. Cancer Sci. 2010;100(5):859-865.

21. Koenig WJT. Fibrin(ogen) in cardiovascular disease: an update. Thromb Haemost. 2003;89(4):601-609. doi:10.1055/s-0037-1613566

22. Herrick S, Blanc-Brude O, Gray A, Laurent G. Fibrinogen. Int J Biochem Cell Biol. 1999;31(7):741-746. doi:10.1016/S13572725(99)00032-1

23. Kim S, Nadel JA. Fibrinogen binding to ICAM-1 promotes EGFR-dependent mucin production in human airway epithelial cells. Am J Physiol Lung Cell Mol Physiol. 2009;297(1):L174L183. doi:10.1152/ajplung.00032.2009

24. Song H, Kuang G, Zhang Z, Ma B, Jin J, Zhang Q. The prognostic value of pretreatment plasma fibrinogen in urological cancers: a systematic review and meta-analysis. $J$ Cancer. 2019;10 (2):479-487. doi:10.7150/jca.26989

25. Zhu Z, Wang X, Wang J, et al. Preoperative predictors of early death risk in bladder cancer patients treated with robot-assisted radical cystectomy. Cancer Med. 2019;8(7):3447-3452. doi:10.1002/cam4.2237

26. Zaitsu M, Toyokawa S, Tonooka A, et al. Sex differences in bladder cancer pathology and survival: analysis of a population-based cancer registry. Cancer Med. 2015;4(3):363-370. doi:10.1002/cam4.379

27. Dobruch J, Daneshmand S, Fisch M, et al. Gender and bladder cancer: a collaborative review of etiology, biology, and outcomes. Eur Urol. 2016;69(2):300-310. doi:10.1016/j.eururo.2015.08.037

28. Karakiewicz PI, Shariat SF, Palapattu GS, et al. Precystectomy nomogram for prediction of advanced bladder cancer stage. Eur Urol. 2006;50(6):1254-60; discussion 61-2. doi:10.1016/j.eururo. 2006.06.010

29. Mao W, Ma B, Wang K, et al. Sarcopenia predicts prognosis of bladder cancer patients after radical cystectomy: a study based on the Chinese population. Clin Transl Med. 2020;10(2). doi:10.1002/ ctm2.105

30. Shariat SF, Karakiewicz PI, Suardi N, Kattan MW. Comparison of nomograms with other methods for predicting outcomes in prostate cancer: a critical analysis of the literature. Clin Cancer Res. 2008;14 (14):4400-4407. doi:10.1158/1078-0432.CCR-07-4713

31. Ljungberg B. Kidney cancer: a new nomogram predicting survival in renal cell carcinoma. Nat Rev Urol. 2010;7(8):423-424. doi:10.1038/ nrurol.2010.117

\section{Publish your work in this journal}

Cancer Management and Research is an international, peer-reviewed open access journal focusing on cancer research and the optimal use of preventative and integrated treatment interventions to achieve improved outcomes, enhanced survival and quality of life for the cancer patient.
The manuscript management system is completely online and includes a very quick and fair peer-review system, which is all easy to use. Visit http://www.dovepress.com/testimonials.php to read real quotes from published authors. 